\title{
A Novel Application in Green Chemical Processing Using Reject Brines and Carbon Dioxide as Raw Materials
}

\author{
Hussein Abdel-Aal ${ }^{*}$, K. M. Zohdy ${ }^{1}$, Maha Abdelkreem ${ }^{1}$, \\ S. M.-S. Abdel-Hamid ${ }^{1}$, M. Bassyouni ${ }^{1,2}$ \\ ${ }^{1}$ Department of Chemical Engineering, Higher Technological Institute, Tenth of Ramadan City, Egypt \\ ${ }^{2}$ Department of Chemical and Materials Engineering, King Abdulaziz University, Rabigh, KSA \\ Email: *habdelaal@link.net
}

Received September 22, 2012; revised October 23, 2012; accepted November 15, 2012

\begin{abstract}
In this paper, the concept of "green processing" will be applied, while explaining the role of sustainable development strategy with respect to the environmental issue. Two parameters are considered in the study by utilizing carbon dioxide and reject brine from desalination plants as raw materials to produce valuable chemical products and partially desalinated water.
\end{abstract}

Keywords: Desalination; Brine; Green Processing

\section{Introduction}

Sustainable development is simply defined as the development that meets the needs of the present without compromising the ability of future generations to meet their own needs [1-3] and ensure that our actions and decisions today do not inhibit the opportunities of future generations. For example, if you list clean air to breath as one of our main objectives where you live nearby an industrial complex, then our needs might conflict. Sustainable development strategy deals in an integrated way, with economic, environmental and social issues [4-6]. When we speak today of going green, we generally refer to something broader than global warming. The term today includes efforts to conserve our natural resources, reduce our contributions to landfills, and reduce pollution generally [7-9].

\section{Study Objective}

In this work, environmental issue is focusing on two important parameters: brines rejected from desalination plants and atmospheric carbon dioxide.

\subsection{Reject Brines from Desalination Plants}

It is estimated that the world production of desalination water exceeds 30 million cubic meters per day and the desalination market worldwide is expected to reach $\$ 30$ billion by 2015 [10]. One of the major economical and environmental challenges to the desalination industry,

\footnotetext{
"Corresponding author.
}

especially in those countries that depend on desalination for potable water, is the handling of reject brine. Assuming that $50 \%$ of the intake sea water to be desalinated, then about 15 million cubic meters/day of reject brine is produced. The common practice in dealing with these huge amounts of brine is to discharge back into the sea affecting seriously the aquatic life.

\subsection{Atmospheric Carbon Dioxide}

Almost all $\mathrm{CO}_{2}$ emissions (about 96.5\%) come from fossil fuels use [11]. The 3 types of fossil fuels that are used the most are coal, natural gas and petroleum. When fossil fuels are combusted, the carbon stored in them is emitted almost entirely as $\mathrm{CO}_{2}$ causing what is known as the green-house-effect. While $\mathrm{CO}_{2}$ could in theory be extracted from the atmosphere (or the stack gas of a combustion based power plant), most of the $\mathrm{CO}_{2}$ collected in processes is derived from ammonia plants [12].

\section{Global Sustainability through Chemical Production Process: Green Processing}

As stated earlier, reject brines and carbon dioxide are two forms of environmental pollutants that we are facing in the course of obtaining fresh water from sea water [1315]. Solving this problem is pursued by the strategy illustrated in Figure 1.

Details of the chemical production process are illustrated in the block diagram shown next in Figure 2.

The chemical production process involves the following consecutive steps: 


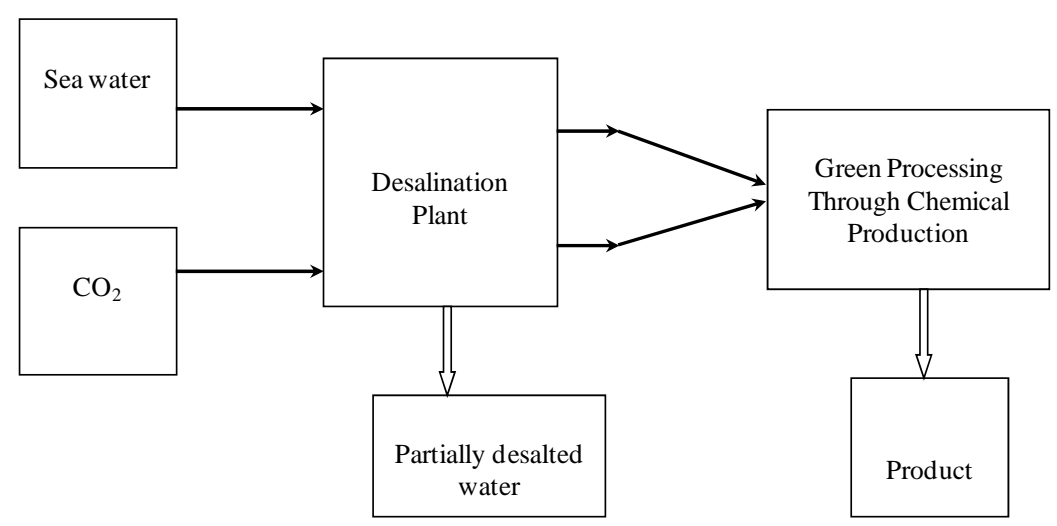

Figure 1. Sustainability for chemical production processes offers a solution for environmental impacts.

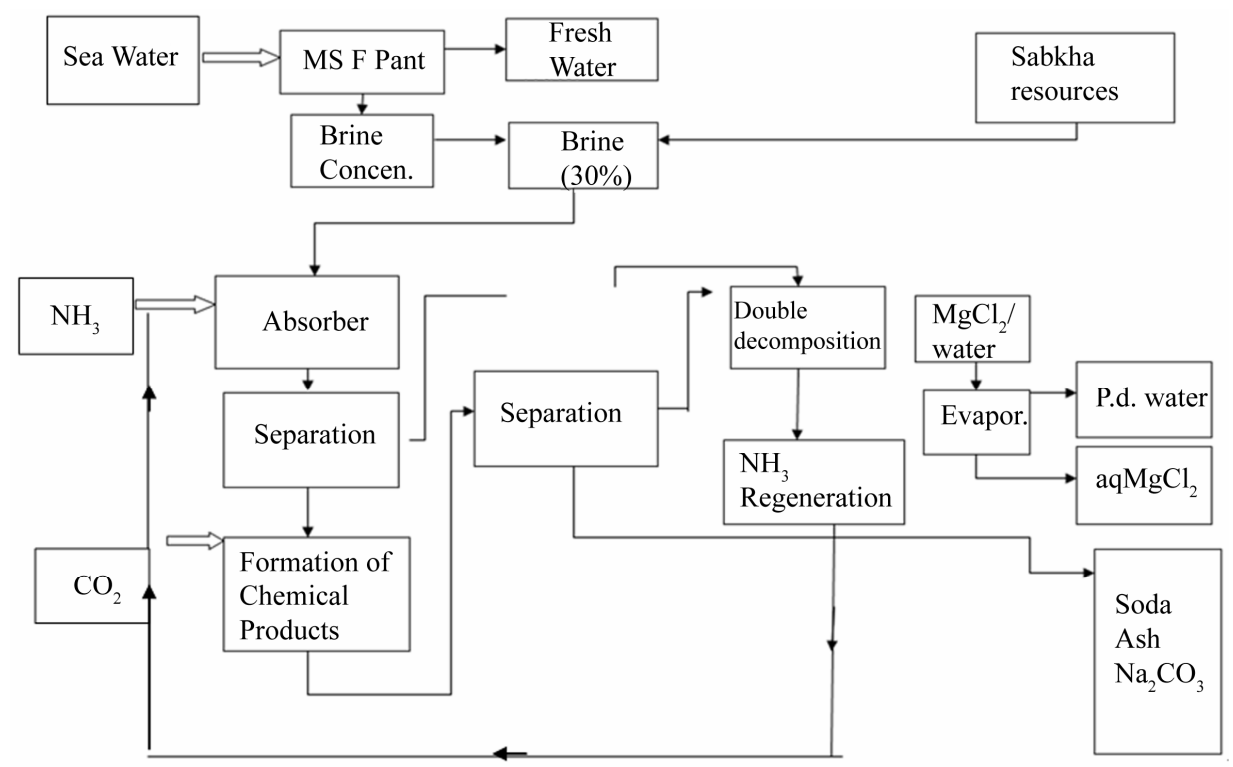

Figure 2. Block flow diagram for global sustainability through chemical production process.

- 1 st Treating saturated brine (30\% sodium chloride) with ammonia gas forming what we call "ammoniated brine".

- 2nd Bubbling carbon dioxide gas into the ammoniated brine will trigger a series of chemical reactions. This will lead to the conversion of both sodium cation and chloride anoion respectively into sodium bicarbonate and ammonium chloride.

- 3rd Sodium bicarbonate precipitates under the experimental conditions and is separated by filtration as a product, leaving ammonium chloride in solution.

- 4th Ammonia gas could be generated and recycled by a double-decomposition chemical reaction with magnesium hydroxide, formed in Step 2 above.

- The overall reaction involved could be visualized to take place as follows:

$$
\mathrm{NH}_{4}+\mathrm{HCO}_{3}^{-}+\mathrm{NaCl} \rightarrow \mathrm{NaHCO}_{3}+\mathrm{NH}_{4} \mathrm{Cl}
$$

- Ammonia regeneration:

$$
\begin{gathered}
\mathrm{NH}_{4} \mathrm{Cl}+\mathrm{Mg}(\mathrm{OH})_{2} \rightarrow \\
\mathrm{NH}_{4} \mathrm{OH}+\mathrm{MgCl}_{2} \\
\downarrow \\
\mathrm{NH}_{3}+\mathrm{H}_{2} \mathrm{O}
\end{gathered}
$$

\section{Reported Experimental Findings}

As presented in reference [16], the main author and coworkers studied experimentally the feasibility of the process. Some of the results are reported next:

a) The Separation of high-salinity synthetic saline water was carried out in a batch gas bubbler using a modified Solvay process. The conversion of $\mathrm{NaCl}$ in the ammoniated brine into $\mathrm{NaHCO}_{3}$ and $\mathrm{NH}_{4} \mathrm{Cl}$ was investigated. The highest conversion of $\mathrm{NaCl}$ achieved was $82.2 \%$.

b) The effect of temperature, initial concentrations of $\mathrm{NH}_{3}$ and $\mathrm{NaCl}$, and the ratio of $\mathrm{NH}_{3} / \mathrm{NaCl}$ were studied. An optimum separation temperature of $22^{\circ} \mathrm{C}$ was found.

c) Indigenous resources of raw materials (such as Sab- 
kha) are abundant in many regions at seashores in countries like Saudi Arabia and Egypt, which can make the chemical separation approach attractive.

Sabkha waters by definition are saline sources containing up to $4-5 \mathrm{~mol} / \mathrm{L}$ of $\mathrm{NaCl}$. When these resources are subjected to the proposed separation process, partially desalted water is obtained along with other valuable chemical products.

\section{Conclusions \& Recommendations}

The experimental findings reported above, triggered the concept of novel application in green chemical processing using reject brines and carbon dioxide as raw materials.

1) The desalination model discussed in this paper presents a study for sustainability through chemical production processes from the environmental point of view.

2) It is highly important to stress that prior integration of sustainability aspects in the chemical process industry during process development to be considered.

3) It is recommended that sustainability studies should be launched for the petroleum sector, where opportunities exist for many by-products to be produced by managing waste streams exit a plant. In waste management the "3 Rs" refer to: "Reduce, Reuse and Recycle", which classify strategies according to their desirability.

4) Ultimately, one should consider the source of $\mathrm{CO}_{2}$ used in a process in order to adequately judge the sustainability of the system.

It should be mentioned that experimental results carried by Abdel-Aal and coworkers are reported in reference [16]. The process was cited and implemented by En Pro Technology [17].

\section{REFERENCES}

[1] S. Dresner, "The Principles of Sustainability," Earthscan Publications Ltd., London, 2002, p. 200.

[2] WCED, “Our Common Future,” Oxford University Press, Oxford, 1987

[3] J. Elkington, “Cannibals with Forks,” Capstone Publishing Limited, Oxford, 2002.

[4] J. L. Hass and F. Brunvoll, "Overview of Sustainable Development," Indicators Used by National and International Agencies, OECD Statistics Working Papers, OECD, Paris, 2002.
[5] IEA, “Energy Technology Perspectives 2008: Scenarios and Strategies to 2050," OECD Publishing, Paris, 2008.

[6] OECD, “2007 Annual Report on Sustainable Development Work in the OECD,” 2007.

http://www.oecd.org/dataoecd/38/21/40015309.pdf

[7] W. E. Eleazer, W. S. Odle, Y.-S. Wang and M. A. Barlaz, "Biodegradability of Municipal Waste Components in Laboratory-Scale Landfills,” Environmental Science \& Technology, Vol. 31, No 3, 1997, pp. 911-917. doi:10.1021/es9606788

[8] USEPA, "Municipal Solid Waste in the United States: 2005 Facts and Figures,” US Environmental Protection Agency, Washington DC, 2006.

[9] M. Huber-Humer, J. Gebert and H. Hilger, "Biotic Systems to Mitigate Landfill Methane Emissions,” Waste Management Research, Vol. 26, No. 1, 2008, pp. 33-46. doi:10.1177/0734242X07087977

[10] M. Schorr, "Desalination, Trends and Technologies", In Tech, 2011.

[11] B. Gugele, M. Ritter and K. Mareckova, "Greenhouse Gas Emission Trends in Europe, 1990-2000,” Topic Report 7/2002, European Environment Agency.

[12] E. J. Beckman, "Supercritical and Near-Critical $\mathrm{CO}_{2}$ in Green Chemical Synthesis and Processing” The Journal of Supercritical Fluids, Vol. 28, No. 2-3, 2004, pp. 121191. doi:10.1016/S0896-8446(03)00029-9

[13] K. Al-Anezi, C. Somerfield, D. Mee and N. Hilal, "Parameters Affecting the Solubility of Carbon Dioxide in Seawater at the Conditions Encountered in MSF Desalination Plants,” Desalination, Vol. 222, No. 1-3, 2008, pp. 548-571. doi:10.1016/j.desal.2007.01.128

[14] M. Ahmed, W. H. Shayya, D. Hoey and J. Al-Handaly, "Brine Disposal from Reverse Osmosis Desalination Plants in Oman and the United Arab Emirates," Desalination, Vol. 133, No. 2, 2001, pp. 135-147. doi:10.1016/S0011-9164(01)80004-7

[15] S. A. Abdul-Wahab and M. A. Al-Weshahi, "Brine Management: Substituting Chlorine with On-Site Produced Sodium Hypochlorite for Environmentally Improved Desalination,” 2009. http://www.pedz.uni-mannheim.de/daten/edz-bn/eua/00/t opic_6_2000.pdf

[16] H. K. Abdel-Aal, A. A. Ibrahim, M. A. Shalabi and D. K. Al-Harbi, "Chemical Separation Process for Highly Saline Water,” Industrial Engineering Chemistry Research, Vol. 35, No. 3, 1996, pp. 799-804. doi:10.1021/ie9405706

[17] ENPRO, Inc. http://www.enpro.no/en/technology.php 